\title{
Presentations of pyogenic liver abscess in one UK centre over a 15-year period
}

\author{
${ }^{1} \mathrm{NC}$ Bosanko, ${ }^{2} \mathrm{~A}$ Chauhan, ${ }^{3} \mathrm{M}$ Brookes, ${ }^{4} \mathrm{M}$ Moss, ${ }^{5} \mathrm{PG}$ Wilson \\ ${ }^{1}$ Specialist Registrar in Gastroenterology; ${ }^{2}$ Senior House Officer; ${ }^{3}$ Consultant Gastroenterologist; ${ }^{4}$ Consultant Radiologist; ${ }^{5}$ Consultant \\ Gastroenterologist, Sandwell and West Birmingham NHS Trust, Birmingham, UK
}

ABSTRACT Background and aim: Pyogenic liver abscess (PLA) has been a condition of high mortality, improving over recent decades with combined antibiotic and percutaneous drainage. We aimed to identify the presenting features, diagnosis, microbiology, treatment and outcome for patients over a I5-year period at an inner-city hospital.

Methods: Patients with an appropriate discharge diagnosis were identified and case records retrospectively analysed.

Results: A total of 73 patient records were analysed. Common presenting features were anorexia, abdominal pain, fever, vomiting and weight loss with raised white cell count, C-reactive protein, alkaline phosphatase and hypoalbuminaemia. The delay following symptom onset to presentation was a mean of I7.3 days. The inclusion of PLA as a possible diagnosis on admission was only considered in $1 \%$ of cases. Positive blood or abscess culture was achieved in $63 \%$ of cases. We recorded a hospital mortality rate of II\%.

Conclusions: In this sample, PLA was rarely considered as a possible diagnosis at presentation. There are common presenting features, which should prompt early investigation. Our microbiological yield was lower than in some studies and may be due to the early empirical use of antibiotics, without microbiological guidance. Percutaneous drainage and antibiotic treatment remain the mainstay of management. The underlying cause for PLA is often not identified. Emerging septicaemia or underlying malignancy were strong predictors of mortality.

Correspondence to NC Bosanko, I Wiscombe Avenue, Penkridge, Stafford STI9 5EH, UK

tel. $+44(0) 7790021066$

e-mail nickbosanko@doctors.net.uk

KEYWORDS Pyogenic liver abscess

DECLARATION OF INTERESTS No conflict of interests declared.

\section{INTRODUCTION}

Pyogenic liver abscess (PLA) remains a condition associated with mortality, but in recent decades, with the advent of combined antibiotic therapy and percutaneous abscess drainage, the mortality has dropped from nearly $100 \%$ to $6-31 \%$.' This combination has become the mainstay of treatment in most centres. ${ }^{2}$ Incidence has been recently identified to be 3.6 per 100,000 population in one large American study, ${ }^{3}$ but there is evidence of significant geographic variation, particularly in Far Eastern populations, where the incidence in Taiwan was recently estimated to be 17.6 per 100,000 population. ${ }^{4}$ We wished to study the presentation patterns and outcomes of patients with PLA who presented in one multi-ethnic urban centre in the UK over a 15-year period.

\section{METHODS}

We searched the hospital's clinical coding database for all patients with the final diagnosis of 'liver abscess' or 'pyogenic liver abscess', between 1993 and 2008. The trust is a large teaching hospital serving a catchment population of about 500,000. The medical records were reviewed and data were extracted relating to patient demographics, medical history, presenting symptoms, initial investigations and working diagnosis on presentation. We also recorded the location of abscess, microbiology data, treatment and patient outcome.

\section{RESULTS}

A total of 86 patients were identified from the hospital database. Of these, 73 medical records were available to analyse. The remaining records were either not found (six) or no information relating to liver abscess was found in the record (seven). This may have been due to miscoding of the diagnosis and predominantly affected case notes from the early part of the study period. The false negative rate is unknown.

\section{Patient demographics}

A total of 53 patients (73\%) were male and 20 female (27\%). The mean age was 64.7 years (standard deviation, SD: 17; range: 2 I-93). Ethnically, 5 I patients (70\%) were Caucasian, I3 Asian (18\%), five Chinese (7\%) and four Afro-Caribbean (5\%). Background medical problems identified included hypertension (12,16\%), ischaemic heart disease $(6,8 \%)$, diabetes mellitus $(7,10 \%)$ and bowel cancer $(5,7 \%)$. No previous medical problems were noted in $14(19 \%)$ of patients. 


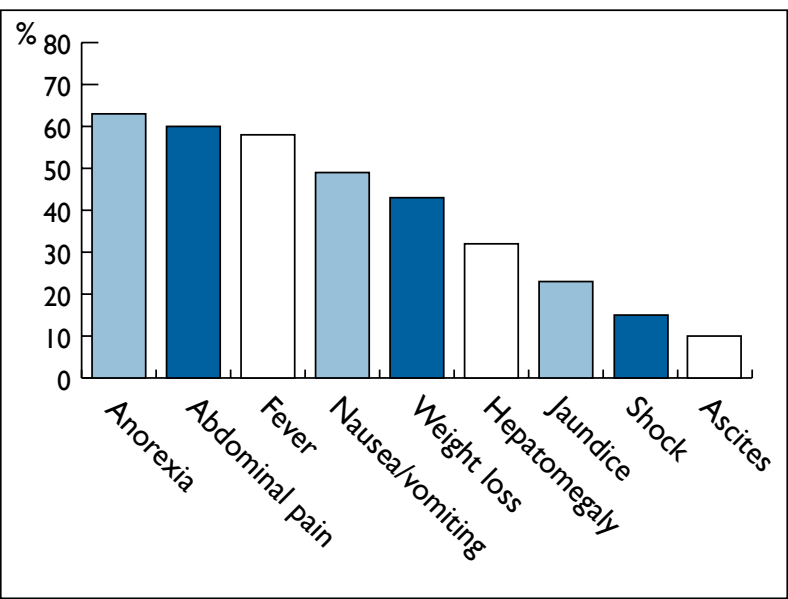

FIGURE I Percentage of patients with various clinical features on presentation.

\section{Diagnosis}

The average duration of symptoms prior to admission was I7.3 days (SD: 25.6; range: I-I68). Presenting features for patients with a subsequent diagnosis of PLA are shown in Figure I and initial laboratory data in Table I.

Clinical evaluation of baseline chest radiograph was documented in 59 cases $(81 \%)$. Thirty-five $(59 \%)$ of these were normal, while nine (15\%) showed a right-sided pleural effusion, six (10\%) suggested consolidation and four $(7 \%)$ suggested a raised right hemidiaphragm. Five showed other features: rib fractures (one), cardiomegaly (three) and radiographic signs of pulmonary oedema (one).

The initial diagnostic differentials formed by the admitting medical team varied widely. Liver abcess was the proposed admitting diagnosis in only one case (I\%).

The mean time to diagnosis following admission was 4.4 days (SD: 3.6; range 0-19) and the method of confirmation of the diagnosis was by abdominal ultrasound in 56 patients $(77 \%)$, computed tomography (CT) in 12 (16\%), ultrasound and computed tomography in four $(5 \%)$ and by exploratory laparotomy in one (1\%). Abscesses were confined to the right hepatic lobe in $54(74 \%)$, the left lobe in $12(16 \%)$ and in both lobes in seven $(10 \%)$. There were solitary abscess in $49(67 \%)$ of patients, two abscesses in eight $(1 \mathrm{l} \%)$ and three or more in $16(22 \%)$.

\section{Microbiology}

Blood cultures were recorded as taken from 66 patients $(90 \%)$. The mean time for taking samples was on day 2.6 of admission (SD: 2.95; range I-22). Abscess culture (via percutaneous aspiration) was documented in 71 cases (97\%). Two patients had positive blood cultures in the presence of advanced malignancy and percutaneous sampling or drainage was deemed clinically inappropriate. The mean time from admission to obtaining culture specimens was 6.7 days (SD: 5.7; range 2-27). A total of 61 (84\%) had both blood and abscess culture. One
TABLE I Laboratory data

\begin{tabular}{|l|l|l|l|}
\hline Parameter & $\begin{array}{l}\text { Mean } \\
\text { value }\end{array}$ & $\begin{array}{l}\text { Standard } \\
\text { deviation }\end{array}$ & $\begin{array}{l}\text { Percentage } \\
\text { with abnormal } \\
\text { value }\end{array}$ \\
\hline $\begin{array}{l}\text { Haemoglobin }(\mathrm{g} / \mathrm{dl}) \\
\mathrm{n}=73\end{array}$ & $1 \mathrm{I} .18$ & 2.0 & $\begin{array}{l}<10 \mathrm{~g} / \mathrm{dl} \\
19\end{array}$ \\
\hline $\begin{array}{l}\text { White cell count } \\
\left(\mathrm{I} 0^{9} / \mathrm{l}\right) \mathrm{n}=73\end{array}$ & 19.8 & 7.5 & $\begin{array}{l}>10 \times 10^{9} / \mathrm{l} \\
93\end{array}$ \\
\hline $\begin{array}{l}\text { C-reactive protein } \\
(\mathrm{mg} / \mathrm{l}) \mathrm{n}=45\end{array}$ & 267 & 125 & $\begin{array}{l}>10 \mathrm{mg} / \mathrm{l} \\
100\end{array}$ \\
\hline $\begin{array}{l}\text { Bilirubin }(\mu \mathrm{mol} / \mathrm{l}) \\
\mathrm{n}=73\end{array}$ & 29.2 & 31.8 & $\begin{array}{l}>22 \mu \mathrm{mol} / \mathrm{l} \\
38\end{array}$ \\
\hline $\begin{array}{l}\text { Alanine transaminase } \\
(\mathrm{U} / \mathrm{l}) \mathrm{n}=73\end{array}$ & 94.1 & 72.1 & $\begin{array}{l}>60 \mathrm{U} / \mathrm{l} \\
63\end{array}$ \\
\hline $\begin{array}{l}\text { Alkaline phosphatase } \\
(\mathrm{U} / \mathrm{l}) \mathrm{n}=73\end{array}$ & 378.4 & 249.8 & $\begin{array}{l}>145 \mathrm{U} / \mathrm{l} \\
85\end{array}$ \\
\hline Albumin $(\mathrm{g} / \mathrm{l}) \mathrm{n}=73$ & 29.2 & 4.6 & $<35 \mathrm{~g} / \mathrm{l} 95$ \\
\hline
\end{tabular}

TABLE 2 Microbiology data

\begin{tabular}{|l|l|l|l|l|l|}
\hline $\begin{array}{l}\text { Positive } \\
\text { organism } \\
\text { in blood } \\
\text { or } \\
\text { abscess } \\
\text { fluid } \\
\mathrm{n}=72\end{array}$ & $\begin{array}{l}\text { Positive } \\
\text { blood } \\
\text { cultures } \\
\mathrm{n}=66\end{array}$ & $\begin{array}{l}\text { Positive } \\
\text { abscess } \\
\text { culture } \\
\mathrm{n}=7 \mathrm{I}\end{array}$ & $\begin{array}{l}\text { Both } \\
\text { positive } \\
\text { (same } \\
\text { organism) } \\
\mathrm{n}=6 \mathrm{I}\end{array}$ & $\begin{array}{l}\text { Both } \\
\text { positive } \\
\text { (different } \\
\text { additional } \\
\text { organism) } \\
\mathrm{n}=6 \mathrm{I}\end{array}$ & $\begin{array}{l}\text { Both } \\
\text { negative } \\
\mathrm{n}=6 \mathrm{I}\end{array}$ \\
\hline $\begin{array}{l}45 \\
(63 \%)\end{array}$ & $\begin{array}{l}25 \\
(38 \%)\end{array}$ & $\begin{array}{l}43 \\
(61 \%)\end{array}$ & $\begin{array}{l}10 \\
(16 \%)\end{array}$ & $\begin{array}{l}6 \\
(10 \%)\end{array}$ & $\begin{array}{l}24 \\
(39 \%)\end{array}$ \\
\hline Organism & $\begin{array}{l}\text { Frequency } \\
\text { (percentage) } \\
\mathrm{n}=5 \mathrm{I}\end{array}$ \\
\hline Gram-positive aerobes & $6(12 \%)$ \\
\hline Streptococcus milleri & $6(12 \%)$ \\
\hline Other Streptococcus spp. & $5(10 \%)$ \\
\hline Streptococcus intermedius & $3(6 \%)$ \\
\hline Haemolytic Streptococcus group G \\
\hline Enterococcus faecium & $3(6 \%)$ \\
\hline Staphylococcus aureus & $2(4 \%)$ \\
\hline Methicillin-resistant S. aureus & $2(4 \%)$ \\
\hline Enterococcus faecalis & $2(4 \%)$ \\
\hline Gram-negative aerobes & $5(10 \%)$ \\
\hline Escherichia coli & $12(24 \%)$ \\
\hline Klebsiella spp. & $5(10 \%)$ \\
\hline Gram-negative anaerobes \\
\hline Bacteroides spp. \\
\hline
\end{tabular}

patient had neither blood nor abscess culture due to advanced malignancy. Microbiological data are shown in Table 2.

The overall microbiological yield for patients who had blood or abscess culture was $63 \%$. Twenty-four patients grew no organisms from blood or abscess and, within this group, the mean duration from starting antibiotics 
to taking blood culture was I.I days (SD: I.2; range: I-4). The mean duration from starting antibiotics to obtaining abscess culture was $5 . I$ days (SD: 5.4; range I-2I). A total of $5 \mathrm{I}$ organisms were isolated in 45 patients.

\section{Management}

\section{Antibiotic therapy}

A total of 72 patients (99\%) received intravenous followed by oral antibiotics. One patient received palliative care only. Seventeen patients $(24 \%)$ received first-line antibiotics only, lasting for a mean of 25.5 days (SD: 20.6; range 3-56). Thirty-three patients (46\%) were changed to second-line antibiotics with a mean total antibiotic treatment of 26.I days (SD:15.2; range 5-62). Twenty-two (3l\%) were changed on to third-line antimicrobials and underwent a mean treatment duration of 33.3 days (SD: 24.I; range 3-1 I8). First-line antibiotic treatment was based on a third-generation cephalosporin plus anti-anaerobic treatment in 53 patients (74\%). A penicillin with anti-anaerobic treatment was used in 14 cases (19\%). The remaining antimicrobial choices represented a range of alternative diagnoses on admission such as presumed urinary tract infection (three patients) and/or non specific cellulitis (two patients). Second- and third-line antibiotics were prescribed based on culture results or local microbiological advice.

\section{Percutaneous drainage}

Percutaneous abscess drainage was performed on 66 patients (90\%). Reasons for not draining abscess included patients with advanced malignancy or due to technical difficulties such as the small size or location of multiple abscesses. The mean time from admission to drainage (where undertaken) was 9.5 days (SD:7.2; range 2-28).

\section{Aetiology}

The underlying aetiology for PLA was unclear in 35 cases (48\%). Benign bowel conditions (diverticulosis, Crohn's disease or appendicitis) were implicated in six cases $(8 \%)$ and malignant conditions in five $(7 \%)$. Benign biliary tract pathology (gall stones, cholangitis, postendoscopic retrograde cholangiopancreatography [ERCP]) were deemed the most likely cause in 17 cases (23\%) and malignant biliary tract disease in nine (I2\%). One patient (I\%) was thought to have developed PLA due to perforated duodenal ulcer.

\section{Complications}

A total of 22 (30\%) of patients developed a pleural effusion during admission, six (8\%) developed ascites and I8 (25\%) had evidence of significant bacteraemia (hypotension and fever).

\section{Outcome}

The mean duration of hospitalisation was 26.8 days (SD: 24. I; range: 4-186). Sixty patients (82\%) were discharged home alive, five $(7 \%)$ were transferred to another care facility and eight ( 1 I\%) died during the index admission.
TABLE 3 Prognostic factors associated with death

\begin{tabular}{|l|l|l|l|}
\hline Factor & $\begin{array}{l}\text { Number } \\
\text { alive }\end{array}$ & $\begin{array}{l}\text { Number } \\
\text { dead }\end{array}$ & $\begin{array}{l}\text { Mortality } \\
(\%)\end{array}$ \\
\hline Age & 44 & 6 & 12 \\
\hline$>60$ & 21 & 2 & 8.7 \\
\hline$\leq 60$ & \multicolumn{5}{|l|}{} \\
\hline Medical history & 5 & 2 & 29 \\
\hline Diabetes & 8 & 4 & 33 \\
\hline Hypertension & 4 & 2 & 33 \\
\hline $\begin{array}{l}\text { Ischaemic heart } \\
\text { disease }\end{array}$ & 4 & 2 & 33 \\
\hline $\begin{array}{l}\text { Pancreatobiliary } \\
\text { cancer }\end{array}$ & 4 & 1 & 20 \\
\hline Bowel cancer & 4 & & \\
\hline Culture (blood
\end{tabular}

Culture (blood or abscess fluid)

\begin{tabular}{|l|l|l|l|}
\hline Positive & $4 \mathrm{I}$ & 4 & 8.9 \\
\hline Negative & 24 & 4 & 14.3 \\
\hline Abscess location & & & \\
\hline Right lobe & 47 & 7 & 13 \\
\hline Left lobe & $1 \mathrm{I}$ & $\mathrm{I}$ & 8.3 \\
\hline Bilobar & 7 & 0 & 0 \\
\hline
\end{tabular}

Evidence of bacteraemia

\begin{tabular}{|c|c|c|c|}
\hline Yes & 12 & 6 & 33 \\
\hline No & 53 & 2 & 3.6 \\
\hline \multicolumn{4}{|c|}{ Admission haemoglobin } \\
\hline$>10 \mathrm{~g} / \mathrm{dl}$ & 52 & 7 & 11.9 \\
\hline$\leq 10 \mathrm{~g} / \mathrm{dl}$ & 13 & 1 & 7.1 \\
\hline
\end{tabular}

Admission white cell count

\begin{tabular}{|l|l|l|l|}
\hline$>10 \times 10^{9} / \mathrm{l}$ & $6 \mathrm{I}$ & 8 & $1 \mathrm{I} .6$ \\
\hline$>20 \times 10^{9} / \mathrm{l}$ & 26 & 5 & 16.1 \\
\hline \multicolumn{4}{|l|}{ Admission serum bilirubin } \\
\hline$>22 \mu \mathrm{mol} / \mathrm{I}$ & 24 & 4 & 14.3 \\
\hline$\leq 22 \mu \mathrm{mol} / \mathrm{l}$ & $4 \mathrm{I}$ & 4 & 8.9 \\
\hline
\end{tabular}

Admission alkaline phosphatase

\begin{tabular}{|l|l|l|l|}
\hline$>145 \mathrm{U} / \mathrm{I}$ & 56 & 6 & 9.7 \\
\hline$\leq 145 \mathrm{U} / \mathrm{I}$ & 9 & 2 & 18.2 \\
\hline \multicolumn{4}{|l|}{ Admission serum albumin } \\
\hline$<35 \mathrm{~g} / \mathrm{I}$ & 62 & 7 & 10.1 \\
\hline$\geq 35 \mathrm{~g} / \mathrm{l}$ & 3 & $\mathrm{I}$ & 25 \\
\hline
\end{tabular}

The mean age of patients who died was 71.8 years (SD:II.4; range: 58-86). Two (25\%) were female and six $(75 \%)$ were male. Four $(50 \%)$ had pre-existing hypertension, two (25\%) had a malignancy (two pancreas, with one patient also having a bowel malignancy), two $(25 \%)$ had ischaemic heart disease and two $(25 \%)$ had diabetes. Four (50\%) developed a presumed septicaemic shock state and one (13\%) developed a nosocomial pneumonia and adult respiratory distress syndrome. All eight $(100 \%)$ patients who died in hospital developed acute renal failure prior to death. The patients who died 
following admission had a mean delay to hospital presentation of 12.2 days (SD: 7.9; range: $2-2 \mathrm{I}$ ). Possible prognostic factors associated with fatality using simple univariate analysis are shown in Table 3. A multifactorial analysis was not possible due to the small sample size.

\section{DISCUSSION}

The average age of patients in our sample of PLA was 65 years. This supports other series in demonstrating that the average age of patients who develop PLA has risen over recent decades, with an average presentation being in the sixth decade ${ }^{5-11}$ or seventh decade. ${ }^{1,12-16}$ As in previous studies, our patients were in general male. . $^{1,3,5,6,8-}$ 10,12,14-16 Background medical history reflected conditions common in the aged population such as diabetes, hypertension and ischaemic heart disease.

There was a mean 'delay' of 17 days to admission following symptom onset and a further subsequent four-day mean delay until a diagnosis of PLA was considered/confirmed. This reflects the rather insidious and non-specific symptomatology that often occurs in PLA. The delay in the confirmation of the diagnosis following admission is of concern. Access to imaging has generally become easier over recent years, thus allowing rapid confirmation of liver abscess where the diagnosis has been considered or in cases where symptoms and signs are ambiguous. Reassuringly, we found little evidence that a delay in imaging (which has been a feature of other published series $^{1,14,17}$ as well as this cohort) affected mortality. Presenting symptoms in our study were typically multiple and non-specific, but commonly included anorexia, fever, nausea and abdominal pain. On physical examination hepatomegaly, jaundice and ascites were often recognised. The low index of suspicion of PLA may be due to this broad symptom clustering in our cohort.

Further clinical information from routine blood tests should suggest the possibility of PLA, particularly the presence of a raised white cell count, C-reactive protein, raised alkaline phosphatase and low albumin, as suggested by other series. ${ }^{1,5,6,8,13,15}$ Baseline chest radiography often showed features that are retrospectively compatible with an associated PLA and diaphragmatic and/or pleural irritation/infection, but the confirmation of the diagnosis clearly relies on specific imaging of the liver. Most PLAs are reliably detectable by ultrasound imaging alone, but the increasing availability of CT - rather than any increase in sensitivity or specificity - is the most likely factor for the $16 \%$ in our cohort being diagnosed by this modality. It is also likely that patients with vague abdominal symptoms and no detected visceral abnormality on basic examination were often referred directly for $\mathrm{CT}$ to image other abdominal organs.

We confirmed the previous suggestion that PLAs are mostly confined to the right hepatic lobe,' which is likely to be the result of the portal venous anatomy. The right lobe also contains a denser network of bile canaliculi and accounts for more hepatic mass.

Abscess drainage has been shown to be beneficial in the treatment of PLA and percutaneous drainage is now standard practice. ${ }^{3}$ Of our cohort, $97 \%$ underwent drainage. One of the main aims is to achieve a positive microbiological diagnosis to further guide antimicrobial management. Our overall microbiological yield, from blood and abscess culture, was 63\%, which is low compared with other studies. A contributory factor to the low microbiological yield may be the early use of antibiotics in non-specific sepsis admission protocols. In our cohort, those with negative blood and abscess culture had received antibiotics, on average, one day prior to blood culture and five days before abscess culture, which will have affected culture yield, as a rapid sterilisation of blood cultures can occur within a few hours of the first antibiotic dose. ${ }^{18}$ The validity of protocols mandating treatment without culture results is reasonable, but the absence of all blood cultures before treatment in this cohort was unusual.

We saw a typical microbiological spectrum which shows a preponderance of Streptococcus species. The other main isolates were E. coli and Klebsiella and Bacteroides species. This predominance of Gram-positive species is in contrast with studies from the Far East, where Gram-negative organisms such as E. coli and Klebsiella reliably top the diagnostic yield tables. ${ }^{12,15}$ One possible explanation is that Gram-positive organisms are likely to be found in patients with infective sources which then spread to form secondary infection in the liver. ${ }^{19}$ Furthermore, cultured organisms are likely to be different in Western urban settings compared with Eastern rural communities.

It is clear that there are patterns of antibiotic resistance, which are likely to increase in the setting of patients with indwelling biliary stents, recurrent cholangitis and multiple courses of antibiotics. ${ }^{20}$ This factor is also important in relation to fungal super-infection. There are little formal data regarding the optimum duration of antibiotic therapy, but most units use a regimen of two weeks' parenteral treatment, followed by a more prolonged course (four to six weeks) of therapy, switching to oral antibiotics when clinical and inflammatory responses allow. ${ }^{21}$ It was unclear in a number of our cohort how long oral antibiotic courses lasted, especially after discharge, hence our figures probably underestimate treatment duration.

As has previously been noted, we were unable to find an underlying cause for PLA in a substantial proportion of patients. ${ }^{9}$ Where a source for PLA was identified, the biliary tract was the most commonly implicated structure. One study identified that ERCP was a useful modality in detecting the cause for PLA in patients where the 
underlying diagnosis was not clear ${ }^{15}$ and may have detected abnormalities in some of the $48 \%$ of our cohort where the aetiology was undetermined. Further clarification of the aetiology of our 'cryptogenic' cases with colonoscopy and ERCP may have improved the identification of underlying lesions. ${ }^{9}$

The in-hospital mortality rate for this small series was II\%. Until the late 1980s the overall mortality rate of PLA remained high at $40 \%,{ }^{22}$ improving with better imaging, more effective use of antibiotics and the trend towards abscess drainage to more contemporary mortality rates of $10-25 \% .^{13}$ Older age ( $>60$ years) and the presence of significant co-morbidity were features associated with higher mortality. Emerging septicaemia and shock was an ominous factor in our cohort and the presence of malignancy was also a predictor of in-hospital death. We could not make a detailed statistical analysis

\section{REFERENCES}

I Ruiz-Hernández J], León-Mazorra M, Conde-Martel A et al. Pyogenic liver abscesses: mortality-related factors. Eur J Gastroenterol Hepatol 2007; 19:853-8. doi: I0.1097/MEG.0b0 I3e3282eeb53b

2 Yu SC, Ho SS, Lau WY et al. Treatment of pyogenic liver abscess: prospective randomized comparison of catheter drainage and needle aspiration. Hepatology 2004; 39:932-8. doi:I0.1002/hep.20I 33

3 Meddings L, Myers RP, Hubbard J et al.A population-based study of pyogenic liver abscesses in the United States: incidence, mortality and temporal trends. Am J Gastroenterol 2010; 105:117-24. doi:I0.1038/ajg.2009.6I4

4 Tsai FC, Huang YT, Chang LY et al. Pyogenic liver abscess as endemic disease, Taiwan. Emerg Infect Dis 2008; 14:1592-600. doi:I0.3201/eid I4I0.07I254

5 Lee KT,Wong SR, Sheen PC. Pyogenic liver abscess: an audit of 10 years' experience and analysis of risk factors. Dig Surg 200I, 18:459-66. doi:10.1159/000050194

6 Rahimian J, Wilson T, Oram V et al. Pyogenic liver abscess: recent trends in etiology and mortality. Clin Infect Dis 2004; 39:1654-9. doi:10.1086/4256I6

7 Chan KS, Chen CM, Cheng KC et al. Pyogenic liver abscess: a retrospective analysis of 107 patients during a 3-year period.Jpn J Infect Dis 2005; 58:366-8.

8 Barakate MS, Stephen MS, Waugh RC et al. Pyogenic liver abscess: a review of 10 years' experience in management. Aust N Z J Surg 1999; 69:205-9. doi:I0.1046/j. I440-1622.1999.01523.x

9 Branum GD, Tyson GS, Branum MA et al. Hepatic abscess: changes in etiology, diagnosis and management. Ann Surg 1990; 21 2:655-62. doi:I0.1097/00000658-1990/2000-00002

10 Seeto RK, Rockey DC. Pyogenic liver abscess. Changes in etiology, management and outcome. Medicine (Baltimore) 1996; 75:99-II3. doi:10.1097/00005792-199603000-00006

II Chou F, Sheen-Chen S, Chen Y et al. Prognostic factors for pyogenic abscess of the liver. J Am Coll Surg 1994; 6:727-32. from our small sample. However, there are some interesting features in this cohort such as those with negative cultures, normal albumin, low alkaline phosphatase and higher haemoglobin apparently being associated with lower mortality. The validity of these associations could only be established with a larger cohort and by multifactorial analysis to exclude confounding associations.

We suggest that with a heightened suspicion for PLA, early radiological diagnosis and subsequent drainage can be performed, and by waiting for culture results in the non-septic patient, targeted antimicrobials can be prescribed, thus reducing antibiotic-associated complications and drug resistance. The continuing potential for evolving severe sepsis should be noted, actively monitored and treated aggressively where it emerges.

12 Kaplan GG, Gregson DB, Laupland KB. Population-based study of the epidemiology of and the risk factors for pyogenic liver abscess. Clin Gastroenterol Hepatol 2004; 2:1032-8. doi:10.1016/SI5423565(04)00459-8

I3 Chu K, Fan S, Lai EC et al. Pyogenic liver abscess: an audit of experience over the past decade. Arch Surg 1996; I3 I:I48-52.

14 Mohsen AH, Green ST, Read RC et al. Liver abscess in adults: ten years experience in a UK centre. Q J Med 2002; 95:797-802.

15 Wong WM, Wong BC, Hui CK et al. Pyogenic liver abscess: retrospective analysis of 80 cases over a 10-year period. J Gastroenterol Hepatol 2002; 17:100I-7. doi:I0.1046/j. I440-1746.2002.02787.x

16 Rintoul R, O'Riordain MG, Laurenson IF et al. Changing management of pyogenic liver adscess. Br J Surg 1996; 83:1215-8. doi:I0.1046/j.I365-2I68.1996.02350.x

17 Alvarez Pérez JA, González JJ, Baldonedo RF et al. Clinical course, treatment, and multivariate analysis of risk factors for pyogenic liver abscess. Am J Surg 200I; I8I:I77-86. doi:10.1016/S00029610(00)00564-X

18 Dellinger RP, Levy MM, Carlet JM et al. Surviving sepsis campaign: international guidelines for management of sepsis and severe sepsis. Crit Care Med 2008; 36:296-327. doi:10.1097/0I. CCM.0000298I58.I2101.4I

19 Lederman ER, Crum NF. Pyogenic liver abscess with a focus on Klebsiella pneumoniae as a primary pathogen: an emerging disease with unique clinical characteristics. Am J Gastroenterol 2005; 100:322-3I. doi:I0.IIII/j.1572-024I.2005.403I0.x

20 Huang CJ, Pitt HA, Lipsett PA et al. Pyogenic hepatic abscess changing trends over 42 years. Ann Surg 1996; 223:600-9. doi:10.1097/00000658-199605000-00016

21 Sharara Al, Rockey DC. Pyogenic liver abscess. Curr Treat Options Gastroenterol 2002; 5:437-42. doi: I0.1007/s I 1938-002-003 I-0

22 Verlenden WL, Frey CF. Management of liver abscess. Am J Surg 1980; |40:53-9. doi: I0.1016/0002-9610(80)904I7-1 